\title{
Young adults' attitudes towards rape and rape victims: effects of gender and social category
}

\begin{abstract}
Violence against women, especially rapes, has been a pervasive problem in the society. It is well documented that victims of rape not only experience serious short and long-term psychological harm as a direct result of the assault, but may also be stigmatized by others (e.g., be blamed for not resisting enough). While there are sufficient studies in the developed countries that have examined how various gender and other ideologies relate to prejudiced attitudes toward rape victims, much less work has been done in developing nations such as India. Because of increased incidents of rapes in the recent past, it becomes increasingly necessary to understand the attitude people form towards rape and rape victims. Thus the present study was planned to understand the prevalent rape myths and attitudes of young adults, and to explore gender and social identity as factors influencing the attitudes towards rape and rape victims. A total of 208 participants, both males and females responded to a Rape Myth Acceptance Scale, Attitude towards Victims Scale and Causal Attribution towards Sexual Violence Scale. Results indicated that compared to male respondents, females hold lesser rape myths but have more negative attitude towards victims of rape. Results also reveal the significant effects of social category and gender on causal attribution for sexual violence. The results of this study are important in improving our understanding of the attitudes young adults hold towards rape and rape victims and present a need to develop strategies to dispel negative stereotypes that individuals hold about victims of rape.
\end{abstract}

\author{
Volume 7 Issue 4 - 2017
}

\author{
Shalini Mittal,' Tushar Singh, ${ }^{2}$ Sunil Kumar \\ Verma $^{3}$ \\ 'Amity Institute of Behavioural and Allied Sciences, Amity \\ University, India \\ ${ }^{2}$ Department of Psychology, Banaras Hindu University, India \\ ${ }^{3}$ Department of Psychology, Vivekanand College, India
}

Correspondence: Tushar Singh, Assistant Professor, Department of Psychology, Banaras Hindu University,Varanasi, UP 221005, India, Email tusharsinghalld@gmail.com

Received: December 01, 2016 | Published: March 20, 2017

Keywords: victims of rape, sexual violence, sexual victimization

\section{Introduction}

Sexual aggression against women has been a problem in the society since time immemorial. Besides minor forms of sexual victimization such as sexist statements, sexually tainted whistles, women often face more serious forms of victimization such as rapes that have been a permeate problem in the society. Even literature, art and historical documents bear evidences to the fact that women across many cultures and throughout the history have been pressured into sexual encounters. ${ }^{1,2}$ The Indian Penal Code of India has defined rape under section 375 as, "A man is said to commit 'rape' who except in the case hereinafter excepted has sexual intercourse with a woman under circumstances falling under any of the six following descriptions:

a. Against her will

b. Without her consent

c. With her consent, when the man knows that he is not her husband and that her consent is given because she believes that he is another man to whom she is or believes herself to be lawfully married

d. With her consent, when her consent has been obtained by putting her or any other person in whom she is interested in fear or death or of hurt

e. With her consent, when at the time of giving such consent by reason of unsoundness of mind or intoxication or the administration by him personally or through another of any stupefying or unwholesome substance, she is unable to understand the nature and consequences of that to which she gives consent

f. With or without her consent when she is under 16years of age.

However, this definition does not include the same sex crimes. So, on February 3, 2003 the definition was aggrandized to include same sex crimes and the age of consent was also raised to18years. Despite the fact that strict legislative provisions have been made to punish those involved in such incidents, the incidents of rapes have been incessantly increasing every day. According to the 2012 statistics of National Crime Records Bureau of India 24,923 rape cases were reported in India in 2012. Out of these 24,470 were committed by relative or neighbor. The annual rape rate in India has increased from 1.9 to 2.0 per 100,000 over the period of $2008-2012$.

The interactive and motivational fundaments of rape are deeply rooted in our cultures. Many investigators are of the view that rape results from the processes of normal socialization..$^{3-6}$ In fact, because most men tend to identify their sexuality with dominance and aggression and women tend to identify their sexuality with dependence and passivity, many women who are raped feel that they were at fault and many of the offenders feel justified by messages that say that rape, sexual harassment, child sexual abuse and other forms of violence are acceptable. It is often unclear to a woman who is raped, whether sexual violation was a result of sexual desire or violent intent. According to the feminist theory ${ }^{7}$ men and women are affected differently by social level variables. For instance, in the current social structure, mostly men dominate over women in terms of work, education and family etc. Dominance is often maintained through violence. ${ }^{8}$ Rape is often an example of such subordination. ${ }^{9}$ Such views are often reflected in the attitudes people hold towards rape in the form of rape myths. A plethora of literature provides evidence for the prevalence of prejudiced attitudes towards rape and rape victims.

\section{Rape myths and rape related attitudes}

The concept of rape myths which was first introduced by sociologists such as Schwendinger and Schwendinger ${ }^{10}$ in 1970s can be defined as a complex set of cultural beliefs that serve to continue male sexual aggression against women by acts like blaming the 
victim and shriving the perpetrator. Examples provided in Lonsway \& Fitzgerald, ${ }^{11}$ explain several important components of the theoretical definition. For example, common rape myths suggest that women often falsely claim being raped and that only "certain kinds of women" are victimized. Many other such myths were keyed out by Burt, ${ }^{6}$ such as "many women secretly wish to be raped", "a healthy woman can successfully resist a rapist if she really wants to", "in the majority of rapes, the victim had a bad reputation", "if a girl engages in necking or petting and she lets things get out of hand, it is her fault if her partner forces sex on her", "men from nice middle class houses never rape". These ideas refuse the fact that sexual victimization is widespread and also deny the personal vulnerability of all women. ${ }^{11}$ The idea that rape myths may be widespread may be determined by the fact that most countries outside North America do not even legally recognize the possibility that rape may occur within marriage. ${ }^{12}$ Some gender differences have also been observed regarding acceptance of rape myths. Shaver ${ }^{13}$ through his theory of defensive attribution reported that males are more accepting of rape myths than females. Many other investigators reported similar results (eg. Burt; ${ }^{6}$ Giacopassi \& Ward. ${ }^{14,15}$ ) Such gender differences may have been observed because of the fact that men do not value sexual consent as much as females do. Petersen et al., ${ }^{16}$ reported that males were more likely than females to feel, "it is okay to manipulate someone into having sex as long as no future promises are made" and "it is alright to pressure someone into having sex". Results of some studies indicate that though males are more accepting of rape myths, they are prevalent among both males and females. ${ }^{11,17}$ However, according to another study no significant difference was observed between males and females in terms of the number of rape myths they enumerated as their personal beliefs. ${ }^{18}$

Rape myths are not only bootless but also damaging for the society. They demoralize the victims and justify the act of crime by supporting the perpetrator. Acceptance of rape myths tends to deny the personal susceptibility of all women to be victimized as they suggest that only bad women are raped. ${ }^{11}$ Research bears evidence that personal relevance plays a major role in safety related interventions. ${ }^{19}$ However, women who hold the rape myth that only 'bad' women are raped are less likely to view rape reduction efforts as personally relevant and as a result are less likely to be a part of it. Men and women who are high on rape myth acceptance are more likely to believe that the sexual assault could have been avoided. ${ }^{20}$ Adherence to traditional gender roles has also been found to be associated with general acceptance of rape myths and with the likelihood of men to commit rape if they were guaranteed that they would not be caught. ${ }^{6}$

It has also been observed that rape victims are often blamed for rape (e.g. Campbell et al., ${ }^{21}$ ) and such blame reactions further intensify the feelings of self blame. ${ }^{22}$ Research indicates that high levels of perpetrator blame are associated with low levels of victim blame. ${ }^{23}$ However, for the same scenarios, certain other studies indicate high levels of victim and perpetrator blame. ${ }^{24}$ Mitchell et al., ${ }^{25}$ found in their research that victims were blamed less when the perpetrator was violently motivated than when the perpetrator was sexually motivated. Pollard ${ }^{26}$ reviewed numerous studies and noted that victims of acquaintance rape were blamed more than victims of stranger rapes. Also, research bears evidence that women blame rape victims less than males. ${ }^{27,28}$ In certain studies no gender differences were observed regarding victim blame..$^{29,30}$ However, in some studies more victim blame was observed among females. ${ }^{31}$ According to Janoff-Bulman ${ }^{32}$ victims of rape tend to blame themselves in two ways- behavioral self blame in which they blame their behavior as a reason for victimization and secondly, characterological self blame in which they tend to blame their personality as a reason for victimization. Fetchenhauer et al., ${ }^{33}$ argued that victims may also blame external factors for their victimization.

The above literature reveals that there are sufficient studies in the developed countries that have investigated how gender and other ideologies relate to invidious rape related attitudes, but much less work has been done in developing nations such as India. Moreover there are very few studies exploring how different rape myths relate to each other and to attitudes towards rape victims. Being a sensitive issue and of great importance, it is crucial to understand the invidious attitudes that people form towards rape and rape victims. Thus, the present study was planned to understand the existing rape myths and rape related attitudes and factors influencing them.

The objectives of this study are to understand how different rape myths inter-correlate with each other and to the attitudes towards rape victims, to understand the prevalent rape myths and attitudes of the young adults towards rape and rape victims and to explore gender and social category as factors influencing the attitudes towards rape victims. It was hypothesized that rape myths would correlate positively and significantly with each other and with negative attitudes towards rape victims. It was also hypothesized that males would hold more rape myths and more negative attitudes towards victims than females and that the participants belonging to the weaker sections of the society (e.g. SC and OBC categories) would hold more negative attitudes towards rape and rape victims than the participants belonging to the general category. Further, it was hypothesized that males would blame the victim more than the females and that the participants belonging to the weaker sections of the society would blame the victims more for their victimization than the participants belonging to the general category.

\section{Methods}

\section{Participants}

A total of 208 graduate and post graduate students, both males and females ( 85 females and 123 males), between the age group of 17-27years, enrolled in different courses, participated in this study.

\section{Tools}

The participants responded to the below mentioned scales.

Updated Illinois Rape Myth Acceptance Scale: Updated Illinois Rape Myth Acceptance Scale is a 22 item measure developed by McMahon \& Farmer..$^{34}$ It has been adopted from the Illinois Rape Myth Acceptance Scale which is a 45 items scale. ${ }^{35}$ Like the original scale, for the updated IRMA, the scores range from 1 for 'strongly agree' to 5 for 'strongly disagree' which may be totaled for a cumulative score. Higher score indicates greater rejection of rape myths. The updated IRMA retains the original subscale categories indicating different rape myths. Subscale 1 stands for the rape myth 'she asked for it', subscale 2 for 'he didn't mean to', subscale 3 for 'it wasn't really rape' and subscale 4 for 'she lied'.

Attitude towards Rape Victims Scale: The Attitude towards Rape Victims Scale is a 25 items scale, developed by C. Ward. ${ }^{15}$ The scale is scored from $0-4$ and a respondent can score from 0-100. For some of the items the scoring is reversed. The higher the score, the more negative the attitudes that the respondent holds towards the rape victims.

Causal Attribution for Sexual Violence Scale: Causal Attribution for Sexual Violence Scale is a 9 items scale developed by Fetchenhauer et al., ${ }^{33}$ for measuring different causal attributions (characterological, behavioral and external) for sexual violence victimization. 
Table I Inter-correlation among different rape myths and with attitude towards rape victims

\begin{tabular}{lllll}
\hline Rape Myths & \multicolumn{2}{l}{ Rape Myths } & Attitude towards Victims@ \\
\hline & He didn't meant it & It wasn't Rape & She Lied \\
\hline She asked for it & $.368^{* *}$ & $.360^{* *}$ & $.455^{* *}$ & $-.670^{* *}$ \\
\hline He didn't meant it & & $.310^{* *}$ & $.262^{* *}$ & -.46 I $^{* *}$ \\
\hline It wasn't rape & & & $.243^{* *}$ & $-.337^{* *}$ \\
\hline She Lied & & & $-.473^{* *}$ \\
\hline
\end{tabular}

**Significant at the 0.0 I level (2-tailed).

$@=$ Higher scores indicate more negative attitude towards rape victims

Table 2 Effect of gender on rape myths and attitudes towards rape victims and causal attribution towards rape victims

\begin{tabular}{|c|c|c|c|c|}
\hline \multicolumn{2}{|l|}{ Variables } & \multicolumn{2}{|l|}{ Gender } & \multirow{2}{*}{$F(1.197)$} \\
\hline Scale & Dimensions & Male $(N=|2|)$ & Female $(\mathbf{N}=82)$ & \\
\hline \multirow{5}{*}{ Rape Myths@ } & She asked for it & 20.31 & 23.08 & $9.26 * *$ \\
\hline & He didn't mean it & 19.90 & 20.74 & 2.30 \\
\hline & It wasn't rape & 19.49 & 20.76 & 2.23 \\
\hline & She lied & 15.86 & 17.65 & $9.87 * *$ \\
\hline & Total Rape Myth & 75.56 & 82.22 & $10.63 * *$ \\
\hline \multirow{2}{*}{$\begin{array}{l}\text { Attitude towards Rape } \\
\text { Victims }\end{array}$} & & 38.75 & 39.73 & $23.43^{* * *}$ \\
\hline & Victim's self & 8.57 & 7.59 & $7.65 * *$ \\
\hline \multirow[t]{2}{*}{ Causal Attribution } & Victim's character & 6.81 & 5.96 & $6.46^{*}$ \\
\hline & External & 8.81 & 8.93 & 0.12 \\
\hline
\end{tabular}

$* \mathrm{p}<0.05$ and $* * * \mathrm{p}<0.001$

@= Lower scores indicate more rape myths.

Table 3 Interaction effect of gender and social categories on rape myths and attitudes towards rape victims and causal attribution for sexual violence

\begin{tabular}{|c|c|c|c|c|c|c|c|c|}
\hline \multicolumn{2}{|l|}{ Variables } & \multicolumn{6}{|l|}{ Gender } & \multirow[t]{3}{*}{$\mathbf{F}$} \\
\hline & & \multicolumn{3}{|l|}{ Male } & \multicolumn{3}{|l|}{ Female } & \\
\hline Scale & Dimensions & General & OBC & SC & General & OBC & SC & \\
\hline \multirow[t]{5}{*}{ Rape Myths } & She Asked for It & 20.4 & 20.06 & 17.81 & 23.74 & 23.97 & 21.96 & $8.97 * *$ \\
\hline & He Didn't Meant & 19.56 & 20.52 & 20.36 & 21.99 & 18.12 & 17.66 & 0.55 \\
\hline & It Wasn't Rape & 19.93 & 18.3 & 18.81 & 21.1 & 10.7 & 19.42 & 0.03 \\
\hline & She Lied & 15.79 & 16.12 & 15.48 & 17.48 & 17.75 & 17.12 &. .01 \\
\hline & Total Rape Myth & 75.68 & 75.01 & 74.48 & 84.33 & 76.54 & 76.16 & 1.2 \\
\hline \multicolumn{2}{|c|}{ Attitude Towards Rape Victims } & 38.61 & 39.82 & 38.46 & 26.42 & 40.44 & 35.49 & $4.27 *$ \\
\hline \multirow[t]{3}{*}{ Causal attribution } & Victim's self & 8.43 & 7.79 & 8.25 & 7.5 & 8.83 & 7 & 0.8 \\
\hline & Victim's Character & 6.97 & 7.14 & 5.15 & 6.07 & 7.59 & 7 & $3.24 *$ \\
\hline & External & 8.78 & 7.63 & 8.5 & 7.2 & 9.93 & 9.17 & 1.12 \\
\hline
\end{tabular}

$* * p<0.01$

\section{Procedure}

Informed consent was taken from all the participants and they were given all the ethics related information. Following which the participants were instructed to respond to the questionnaires. They were informed that the questions were asked only for research purpose and that their responses will be kept strictly confidential. For the purpose of maintaining confidentiality the participants were given an ID. After taking their demographic details the participants responded to a Rape Myth Acceptance Scale, Attitude towards Rape Victims Scale and Causal Attribution for Sexual Violence Scale. After collecting the data it was scored on a five point rating scale. For few items the scoring was reversed.

\section{Results}

The Table 1 above shows the inter-correlation among different rape myths and with attitudes towards rape victims. Results indicate a positive and significant correlation among different rape myths. Results also indicate that rape myths are significantly but negatively related to negative attitudes towards rape victims.
The Table 2 above shows the effect of gender on rape myths, attitudes towards rape victims and causal attribution for sexual violence. Results reveal that compared to females, males have more rape myths that 'she asked for it' and that 'she lied'. Males have less negative attitudes towards victims of rape than females. Results reveal that males blame the victim's behavior and victim's character more as reasons for victimization than females. However, no significant difference was observed between males and females for making external causal attributions.

The Table 3 shows the interaction effect of gender and social categories on rape myths and attitudes towards victims and causal attribution for sexual violence. To see the effect of social category a 2 (gender) x 3 (social category) ANOVA was performed for 203 participants ( 5 subjects were dropped as they were less in number belonging to do not want to reveal and missing categories). The results reveal that no main effects of social category were found in the analysis. However, a significant interaction of gender and social category was found on many dependant measures. It was found that both males and females participants from the general category were more rejecting 
of the rape myth 'she asked for it', followed by participants from OBC and then SC category. Results also reveal that for both males and females, participants from the $\mathrm{OBC}$ category hold more negative attitudes towards victims. Among females, OBC participants blamed the victim's character as a reason for being victimized the most followed by SC and then general category participants. Among males OBC participants blame the victim's character the most followed by participants from general and then SC category.

\section{Discussion}

The present study was an attempt to understand how different rape myths inter-correlate with each other and to negative attitudes towards rape victims, to understand the prevalent rape myths and attitudes of young adults towards rape and rape victims and to explore gender and social category as factors influencing the attitudes towards rape and rape victims. It was hypothesized that rape myths would correlate positively and significantly with each other and with negative attitudes towards rape victims. It was also hypothesized that males would hold more rape myths and more negative attitudes than females and that the participants belonging to the weaker sections of the society (e.g. SC, ST and OBC categories) would hold more negative attitude towards rape and rape victims than the participants belonging to the general category.

The findings of the present study support our hypothesis that rape myths would correlate positively and significantly with each other. This means that people having one type of myth are expected to be high on other types of rape myths. However, the hypothesis that rape myths would correlate significantly and positively to negative attitudes towards rape victims is partially supported. Results indicate that rape myths correlate significantly but negatively to negative attitudes towards rape victims. The results suggest that people holding more rape myths are less likely to hold more negative attitudes towards rape victims. Buddie \& Miller $^{18}$ had argued that it was possible for individuals to plump for rape myths but at the same time they may recognize the negative effects of rape. Buddie and Miller reported that over $57 \%$ of the participants reported some combination of rape myths and behavioral and/or emotional reactions of victims for their personal belief about the victims of rape. This may be the reason that participants who hold more rape myths have less negative attitudes towards the victims of rape. Although they do endorse the rape myths, they also recognize the negative impact that rape has on the victims which causes them to hold less negative attitudes towards rape victims.

The findings of the study partially supported the hypothesis that males would hold more rape myths than females. The results indicate that this statement is true for at least certain kinds of rape myths. It was found that compared to females, males have more rape myths that 'she asked for it' and that 'she lied'. These results are in line of the studies conducted in the past that have confirmed that females are less accepting of rape myths than are males (e.g. Burt \& Field. ${ }^{6,36}$ ) The results refute the hypothesis that males would hold more negative attitudes towards the rape victims. The results obtained are contrary to the results obtained by researches carried out in the past (eg. Jiminez $\&$ Abreu. ${ }^{37}$ ) However, these results may have been obtained because of the fact that more restrictions are placed on women and they are consistently taught to be more traditional than men in our society. Past researches have reported positive relations between traditional gender role stereotypes and rape supportive behaviors. ${ }^{6,38,39}$

The results support the hypothesis that males would blame the victims more than females. The results reveal that males make more behavioral and characterological blame than females. Males have been found to blame the behavior and character of the victim more, as reasons for the victimization, than females. Males have consistently been shown to blame the victims of rape more than the females in the past. ${ }^{27,28}$ Men have also been shown to attribute more responsibility to the victims of rapes and to view rape as less severe than women. ${ }^{40}$

A significant interaction of gender and social category was found on many dependant measures. Results indicate that females were more rejecting of rape myths and that both males and females in the general category were more rejecting of rape myths than the participants from the $\mathrm{OBC}$ and $\mathrm{SC}$ categories. Among the three categories, i.e. general, $\mathrm{OBC}$ and $\mathrm{SC}$, participants in SC category were shown to be most accepting of rape myths. Results reveal that females hold more negative attitudes towards rape victims than males. Among females, OBC participants have more negative attitudes towards rape victims followed by $\mathrm{SC}$ and then participants from the general category. Among males too, $\mathrm{OBC}$ participants have been shown to hold more negative attitudes towards rape victims than General and then SC categories. However, there is very little difference between the participants in general and SC categories in case of males. Nagel et al., ${ }^{41}$ concluded that having a greater income is associated with holding more sympathetic attitudes towards victims of rape. According to the results females blame the victims less than the male participants. Also, among females $\mathrm{OBC}$ and SC participants make more characterological blame than participants in the General category. This means that among female participants, $\mathrm{OBC}$ and SC participants blame the victim's personality more as a reason for the rape than the participants in the general category. Among males as well, OBC participants have been shown to make more characterological blame than participants in the general and SC categories. However, contrary to the common notion, participants from the general category make more characterological blame than the SC participants. No significant differences were found between males and females and among the categories regarding external factors as causes for rape. Despite a significant interaction effect of gender and social category on many dependant measures, no main effect of gender and social category were found in the analysis.

The results indicate that despite increase in education and awareness about social evils such as rapes, there exist rape related myths and negative attitudes towards rape victims in males.

The findings of the present study have important theoretical and practical implications. The present research was an attempt to add to the existing literature and expand on the research regarding rape myths. These results are also important for those working with the justice system as it would improve the awareness of these biases among them along with the victims. Then they can work to counter them. The knowledge of what negative attitudes people hold towards victims of rape can help identify ways to ward these biases, thereby helping to minimize the stigmatization and secondary victimization of rape victims. The findings of this research will aid both rape victims and those meeting rape victims in understanding the processes that play a crucial role in the social perception of rape and rape victims.

\section{Limitations and further suggestions}

The results of this study are only indicative and subject to few limitations. The study used only a small sample of 208 participants. A bigger sample is needed for validation of these findings. Gender and category wise the sample distribution was unequal. Future studies must use a sample that is gender and category wise, equally distributed. Study involved the use of questionnaire survey responses which might have been affected by social desirability. Future studies 
may use more indirect measures that might give more accurate results. Future studies may also explore the conditions in which these prejudiced rape related attitudes develop.

\section{Acknowledgments}

None.

\section{Conflicts of interest}

Author declares there are no conflicts of interest.

\section{Funding}

None.

\section{References}

1. Brownmiller S. Against our will: Men, women and rape. Ballantine Books, New York, USA. 1975.

2. Zeitlin F. Configurations or rape in Greek Myth. In: Tomaselli \& Porter (Eds.), Rape: An historical and social enquiry, Basil Blackwell, New York, ,USA. 1986. p.122-151.

3. Jackson S. The social context of rape: Sexual scripts and motivation. Women's Studies International Quarterly. 1978;1(1):27-38.

4. Russel DEH. Sexual exploitation. Beverly Hills, Sage, CA. 1984.

5. Weis K, Weis S. Victimology and justification of rape. In: Drapkin \& Viano (Eds.), Victimology: A new focus, Heath, Lexington, MA, USA. 1975 .

6. Burt MR. Cultural myths and supports for rape. J Pers Soc Psychol. 1980;38(2):217-230.

7. Yodanis C. Gender inequality, violence against women and fear: A cross-national test of the feminist theory of violence against women. $J$ Interpers Violence. 2004;19(6):655-675.

8. Anderson I, Doherty K. Accounting for rape: Psychology, feminism \& discourse analysis. Routledge, London, UK. 2007.

9. Rozee PD. Rape resistance: Success and challenges. In: Barnes (Ed.), The handbook of women, psychology and the law San Fancisco, Jossey Bass, CA, USA. 2005. p.265-279.

10. Schwendinger JR, Schwendinger H. Rape myths: In legal, theoretical and everyday practice. Crime and Social Justice. 1974;1:18-26.

11. Lonsway KA, Fitzgerald LF. Rape myths: in review. Psychology of Women Quarterly. 1994;18:133-164.

12. Koss MP, Heise L, Russo NF. The global health burden of rape. Psychology of Women Quarterly. 1994;18(4):509-537.

13. Shaver KC. Defensive attribution: Effects of severity and relevance on the responsibility assigned for an accident. Journal of Personality and Social Psychology. 1970;14:101-113.

14. Giacopassi D, Dull RT. Gender and racial differences in the acceptance of rape myths within a college population. Sex Roles. 1986;15(1):63-75.

15. Ward C. The Attitudes Toward Rape Victims Scale: Construction, Validation, and Cross-Cultural Applicability. Psychology of Women Quarterly. 1988;12(2):127-146.

16. Petersen JL, Hyde JS. Gender Differences in sexual attitudes. $J$ Sex Res. $1985 ; 48(2-3): 1630-1642$.

17. Brady EC, Chrisler JC, Hosdale DC, et al. Date rape: Expectations, avoidance strategies and attitudes towards victims. J Soc Psychol. 1991;131(3):427-429.

18. Buddie AM, Miller AG. Beyond rape myths: A more complex view of perceptions of rape victims. Sex Roles: A Journal of Research. 2001;45(3):139-160.
19. Markova I, Power K. Audience response to health messages about AIDS. In: Edgar \& Freimuth (Eds.), AIDS: A communication perspective, Hillsdale, Erlbaum, NJ, USA. 1992.

20. Kopper BA. Gender, gender identity, rape myth acceptance and time of initial resistance on the perception of acquaintance rape blame and availability. Sex Roles. 1996;34(1):81-93.

21. Campbell R, Ahrens CE, Sefl T, et al. Social reactions to sexual assault victims: Healing and hurtful effects on psychological and physical health outcomes. Violence Vict . 2001;16(3):287-302.

22. Ullman SE, Filipas HH, Townsend SM, et al. Psychosocial correlates of PTSD symptom severity in sexual assault survivors. J Trauma Stress. 2007;20(5):821-831.

23. Brown AL, Testa M. Social influences on judgments of rape victims: The role of the negative and positive social reactions of others. Sex Roles. 2008;58(7):490-500.

24. Frese B, Moya M, Megías JL. Social perception of rape: How rape myth acceptance modulates the influence of situational factors. $J$ Interpers Violence. 2004;19(2):143-161.

25. Mitchell D, Angelone DJ, Kohlberger B, et al. Effects of offender motivation, victim gender and participant gender on perceptions of rape victims and offenders J Interpers Violence. 2009;24(9):1564-1578

26. Pollard P. Judgments about victims and attackers in depicted rapes: A review. Br J Soc Psychol. 1992;31(Pt 4):307-326.

27. Cowan G. Beliefs about the causes of four types of rape. Sex Roles. 2000;42(9):807-823.

28. Whatley MA, Riggio RE. Gender differences in attributions of blame for male rape victims. Journal of Interpersonal Violence. 1993;8(4):502-511.

29. Newcombe PA, van den Eydne J, Hafner D, et al. Attributions of responsibility for rape: Differences across familiarity of situations, gender and acceptance of rape myths. Journal of Applied Social Psychology. 2008;38(7):1736-1754.

30. Stromwall LA, Alfredsson H, Landstrom S. Rape victim and perpetrator blame and the just world hypothesis: The influence of victim gender and age. Manuscript submitted for publication. 2011;19(2):207-217.

31. Grubb AR, Harrower J. Attribution of blame in cases of rape: An analysis of participant gender, type of rape and perceived similarity to the victim. Aggression and Violent Behaviour. 2008;13:396-405.

32. Janof-Bulman R. Characterological versus behavioral self blame: Inquiries into depression and rape. J Pers Soc Psychol. 1979;37(10):1798-1809.

33. Fetchenhauer D, Gabriele J, Belschak F. Belief in a just world, causal attributions and adjustment to sexual violence. Social Justice Research. 2005;18(1):25-42.

34. McMahon S, Farmer GL. An updated measure for assessing subtle rape myths. Social Work Research. 2011;35(2):71-81.

35. Payne DL, Lonsway K, Fitzgerald LF. Rape myth acceptance: Exploration of its structure and its measurement using the Illinois Rape Myth Acceptance Scale. Journal of Research in Personality. 1999;33(1):27-68

36. Feild HS. Attitudes towards rape: A comparative analysis of police, rapists, crisis counselors, and citizens. Journal or Personality and Social Psychology. 1978;36(2):156-179.

37. Jiminez JA, Abreu JM. Race and sex effects on attitudinal perceptions of acquaintance rape. Journal of Counseling Psychology. 2003;50(2):252-256.

38. Anderson WP, Cummings K. Women's acceptance of rape myths and their sexual experiences. Journal of College Student Development. 1993;34(1):53-57. 
39. Check JVP, Malamuth NM. Sex role stereotyping and reactions to depictions of stranger versus acquaintance rape. Journal of Personality and Social Psychology. 1983;45(2):344-356.

40. Deit SR, Littman M, Bentley BJ. Attribution of responsibility for rape: The influence of observer empathy, victim resistance and victim attractiveness. Sex roles. 1984;10(3):261-280.
41. Nagel B, Matsuo H, McIntyre KP, et al. Attitudes towards victims of rape: Effects of gender, race, religion and social class. $J$ Interpers Violence. 2005;20(6):725-737. 